\title{
Science Communication Versus Science Education: The Graduate Student Scientist As A K-12 Classroom Resource
}

Jeff Strauss, (Email: jstraus@calstatrla.edu), California State University, Los Angeles Richard E. Shope III, (Email: mime@shope.com), University of Southern California Susan Terebey, (Email: sterebe@calstatrla.edu), California State University, Los Angeles

\begin{abstract}
Science literacy is a major goal of science educational reform (NRC, 1996; AAAS, 1998; NCLB Act, 2001). Some believe that teaching science only requires pedagogical content knowledge (PCK) (Shulman, 1987). Others believe doing science requires knowledge of the methodologies of scientific inquiry (NRC, 1996). With these two mindsets, the challenge for science educators is to create models that bring the two together. The common ground between those who teach science and those who do science is science communication, an interactive process that galvanizes dialogue among scientists, teachers, and learners in a rich ambience of mutual respect and a common, inclusive language of discourse (Stocklmayer, 2001). The dialogue between science and non-science is reflected in the polarization that separates those who do science and those who teach science, especially as it plays out everyday in the science classroom. You may be thinking, why is this important? It is vital because, although not all science learners become scientists, all $\mathrm{K}$ - 12 students are expected to acquire science literacy, especially with the implementation of the No Child Left Behind Act of 2001 (NCLB). Students are expected to acquire the ability to follow the discourse of science as well as connect the world of science to the context of their everyday life if they plan on moving to the next grade level, and in some states, to graduate from high school.
\end{abstract}

This paper posits that science communication is highly effective in providing the missing link for $K$ 12 students' cognition in science and their attainment of science literacy. This paper will focus on the "Science For Our Schools" (SFOS) model implemented at California State University, Los Angeles (CSULA) as a project of the National Science Foundation's GK-12 program, (NSF 2001) which has been a huge success in bridging the gap between those who "know" science and those who "teach" science. The SFOS model makes clear the distinctions that identify science, science communication, science education, and science literacy in the midst of science learning by bringing together graduate student scientists and science teachers to engage students in the two world's dialogue in the midst of the school science classroom. The graduate student scientists and the science teachers worked as a team throughout the school year and became effective science communicators as they narrowed the gulf between the two worlds.

Most of the fundamental ideas of science are essentially simple, and may, as a rule, be expressed in a language comprehensible to everyone. -Albert Einstein

\section{INTRODUCTION}

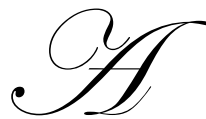

little less than fifty years ago, novelist and scientist C.P. Snow (1959) postulated in the Rede Lecture that "The whole of western society is increasingly being split into two polar groups." With scientists at one pole and non-scientist literary intellectuals at the other he observed that between the two there was a vast "lack of understanding" (p.4). This is analogous to the problem of intercultural communication. Like two cultures separated by a vast ocean, each polar group develops its own divergent discourse. Reconciliation of Snow's 
two worlds requires science communication. While this "two worlds" debate still rages --unresolved-- there is a similar schism between those who do science and those who teach science. There exists a venue that stands directly in the middle of this dialectic: the school science classroom. As students enter the classroom, they step from their everyday non-science world into the very different culture of science content, language, history and thought. The national goal to achieve science literacy resolves this two-worlds split. For some the transition is easy, but for others the struggle begins.

Scientists are involved in doing science and exploring the unknown (Valiela, 2001), whereas science educators are involved in teaching science content knowledge that is already known and organized into national and state standards, as a foundation for science literacy and entry into science-related careers. Students are involved in learning school science, typically responding to questions and memorizing the answers that will appear on the test. For many K-12 students, learning to do science is limited to textbook-driven "hands-on activities" and step-by-step "cookbook labs." Unless these students are in gifted programs or Advanced Placement classes, the experience of authentically doing science, truly exploring the unknown, is not usually part of school science. That is, students are not usually encouraged to generate their own questions, seek support for their own research project, and confer with colleagues to share their own significant results, or publish their own writings in peer-reviewed journals - students are not sufficiently engaged in the dialogue of doing science.

Teaching science requires pedagogical content knowledge (PCK) (Shulman, 1987); whereas, doing science requires knowledge of the methodologies of scientific inquiry (NRC, 1996). Many scientists and science teachers have both capabilities, but in general, these two roles tend to be polarized, similar to Snow's two worlds. The common ground between those who teach and those who do is science communication.

Science communication is the explicit intercultural discourse that explains the significance of scientific research, the nature of science, the doing of science, and the content of science. Science communication is an interactive process. When science communication occurs in the presence of science learners, it galvanizes dialogue among scientists, teachers, and learners in a rich ambience of mutual respect and a common, inclusive language of discourse (Stocklmayer, 2001). Each perspective brings its own unique contribution to the table. The challenge is to create models of this multi-tiered dialogue that brings scientist, science teacher, and science learners together in the practical settings that exist in today's learning environment. This paper posits that science communication is highly effective in providing the missing link to a student's cognition in science and attainment of science literacy. While several avenues exist for this concept of science communication to be included within the classroom environment, this paper will focus on the National Science Foundation's GK-12 program, (NSF 2001) and more specifically the "Science For Our Schools" (SFOS) project model implemented at California State University, Los Angeles (CSULA).

\section{ATTAINING SCIENCE LITERACY: THE NEED FOR SCIENCE EDUCATORS AND SCIENTISTS TO COME TOGETHER}

Science literacy is the ability to follow scientific discourse and to connect the world of science to the context of everyday life - the ability to make science personally relevant (American Association for the Advancement of Science (AAAS), 1998). For example, common meanings of words such as "theory," "law," "evidence," and "proof," differ from their precise meanings in the context of scientific discourse. Science literacy includes the ability to relate and connect these two worlds with common words that facilitate students' understanding. The goal of K-12 science education is to ensure that all students attain science literacy and to prepare those who wish to pursue science careers. Not all science learners become professional scientists, but all K-12 students are expected to be able to understand the basics of scientific principles and be able to interpret science writing and understand basic scientific explanation.

Due to the new science testing requirements mandated by the No Child Left Behind Act of 2001, (NCLB 2001) and in line with previous calls for reform, there is national consensus that science education needs to be reformed if all Americans are going to become science literate (NRC, 1996; AAAS, 1998). The collaboration of science education and science communities working together was the impetus for the National Science Foundations GK-12 programs. The goal of the program is to form collaborative partnerships between universities and local public schools using graduate level science majors (graduate student scientists). These graduate student scientists go out into 
the public schools and serve as science communicators in order to "narrow the gulf between the world of school science and the world of scientists" (Thompson, Metzgar, et.al, 2002). In the exchange, the graduate student scientist acts as a resource for the science teacher whose job it is to achieve scientific literacy among K-12 students while experience in the classroom simultaneously increases the scientists' understanding of K-12 science education (p. 7). As such, both parties benefit from the union.

There is ample evidence that the call for science literacy isn't relegated only to the classroom, political agendas, or the halls of academia. People in general are fascinated by science, physics, astronomy, engineering, and technology. In 1976 author Gary Zukav attended a conference of physicists at Esalen Institute in Big Sur California. It inspired him to write The Dancing Wu Li Masters: An Overview of the New Physics because he saw that between the physicists and the non-physicists there "a notable communication problem between the two groups" (Zukav, 1979). This book is still in print some twenty-five years later and enthralls novices to professional physicists alike. Zukav is one of an endless list of authors writing about science topics. Pulitzer Prize winner, John McPhee, has written countless books on geology. Brian Greene wrote Elegant Universe and popular authors like Carl Sagan and Stephan Hawking to name a few, all wrote enormously popular books about science topics.

It is not just the erudite who are fascinated by science. In the article, "The Science of Museums" in Science News, Janet Raloff (1998) tells how the Smithsonian's Hall of Geology, Gems and Minerals draws 5 million visitors annually to see the most viewed museum object in the world- the 45.5-carat Hope diamond. She goes on to say, "Collectively, U.S. science and technology centers bring in more than 130 million visitors each year" (p.184). In that same article this is credited to 'visitor reaction' to the exhibits as much as budgets and planning on part of the museums.

Understanding the relationship between science and technology is also part of science literacy. A. Luis Odom recently wrote about the need for teachers to develop technology skills. He stated, "Science as inquiry is parallel to technology as design, (2002)." Once you begin to "do science", you will notice that much of science involves process skills like observation, measurement, monitoring and other actions that rely on technology. Consequently, due to the importance of technology skills in the teaching of science, science educators must keep pace with the rapid changes in technology and learn how to "integrate technology into the classroom and make it an integral tool for learning within the context of science and science education" (p.1). In other words, teachers must use technology in the classroom if they want to provide their students with the skills necessary to be a scientifically literate adult.

Changing students' perception of who can be a scientist will also be a difficult task. As recently as 1998, S. Patrina concluded a ten year examination of The Journal of Technology Education, and found disturbing, yet familiar, patterns with the literature published therein. Ninety percent of the articles were written by men and at least two thirds of the articles used adults (teachers, university students) as their test subjects, not children (A. Odom et.al. p.7). With data such as this, it is not difficult to understand the survey results of SFOS high school science teacher, Tom Lau of Baldwin Hills High in California. Mr. Lau asked his students to draw their idea of a 'scientist'. For the most part, the students drew a white adult male in a lab coat. These results were consistent with the results of a national study that assessed student's attitudes and perceptions about science (Barman, 1997). It is obvious that changing students' mindset about who can and cannot be a scientist must be a priority of science teachers. Unfortunately, until this happens, it will be difficult to motivate students to choose a career in the sciences.

Learning cycles and other science inquiry-based teaching models seek to connect the student to the world of doing science. This is accomplished by engaging students in "minds-on activities, facilitated by scaffolded dialogue that challenges and elevates learners to new levels understanding (Marek and Cavallo, 1997). Jerome Bruner, commenting on the concept of the Zone of Proximal Development (ZPD), points out that in Vygotsky's view, understanding is catalyzed when scaffolded dialogue occurs between an expert teacher and a less expert learner. "Once a concept is explicated in dialogue, the learner is enabled to reflect on the dialogue. Then the learner can use its distinctions and connections to reformulate his own thought" (Bruner, 1987, p.4). In the classroom, the job of the teacher is to create a zone of guided inquiry, drawing students toward a deeper understanding in the context of doing science. But unless teachers participate in the world of science themselves-and most do not-something will be missing. While the science teacher is an expert in relation to the student, it is the scientist who is an expert in relation 
to the teacher. A crucial piece of the whole puzzle is to ensure that teachers explicitly communicate an accurate picture of the nature of science to their students. However, this missing piece can be put into place. The SFOS GK-12 program is an example of the kind of model "in a practical setting" where the two-world dialogue can take place! Teachers, by and large, are not going to return to college to secure updated science degrees, but in order to advance their own science literacy, they can benefit from scaffolded dialogue with more expert science communicators.

\section{EXISTING MODELS FOR ENHANCING TEACHERS' SCIENCE COMMUNICATION SKILLS}

Various avenues exist for introducing pedagogy and methods into the classroom that will increase science literacy. As instructors and professors in colleges of education and in the natural sciences, the authors are aware that we can now successfully implement many of those models at the pre-service teacher's level. With $82 \%$ of $12^{\text {th }}$ graders nation-wide not proficient in science (McLoughlin 2003, Ukpolo, and Strauss 2005) it is obvious that we must attack the issue of science literacy on multiple levels. At the pre-service level one such program is "Better Educated Science Teachers" (BEST), a secondary science teacher preparation program at California State University, Los Angeles, that blends coursework in science content and pedagogy in a single degree plan. The BEST program was piloted as an alternative route to the California single subject teaching credential beginning in 1999. Because the program blends a B.S. degree in Natural Science with a single subject teaching credential, students must carry unit loads and take courses in a strictly prescribed sequence beginning in the freshman year. However, recruitment is a major challenge few entering freshman are committed to secondary science teaching careers. This could be because of their lack of confidence in their own science background.

Another model that has been given much study, practice and attention is the apprenticeship model. In "Preservice Secondary Science Teacher Apprenticeship Experience with Scientists" (Brown, Bolton, et. al 2001) the authors detail a number of ways in which this model can enhance the science communication skills of pre-service teachers and inservice teacher alike. The program placed preservice and inservice teachers in a one or two-week summer research experience where the teacher/students conduct inquiry experiments with available science mentors and actual laboratory equipment. The teacher/students hypothesize on science questions, collect and analyze data and present that data to their group. Next, they worked on developing inquiry based lessons to take into their classrooms when they begin teaching. Finally the teachers/students were paired with their partnered inservice teacher to reinforce their learning experience (p.7). Helmer, (1997) researched this particular model and concluded that the laboratory model was effective for "exposing preservice teachers to science research and transferring that experience to the classroom." Both aforementioned models presuppose that preservice teachers know that they want to teach science or that the already employed teachers were willing to be reeducated at some level into newer scientific pedagogy.

There is an existing alternative that has proved efficient in enhancing scientific literacy. The pedagogical paradigm is to use manifold avenues of approach to communicate and educate to promote scientific literacy in the classroom. The program is the Science For Our Schools (SFOS) project housed at CSULA. The program is funded by the National Science Foundation (NSF) as part of its GK-12 Program.

\section{WHY THE SFOS MODEL?}

The Science For Our Schools (SFOS) project was designed to place fulltime graduate level science students from the Physics/Astronomy, Chemistry, Geology, and Biology departments into the junior and senior high school classrooms as a resource to the public school science teacher. The participating schools are, by design, minority serving institutions. Once in the classroom, the graduate students develop experiments, create lab projects and make presentations that are aligned with the California State Content Standards specific to the class and grade level they are assigned to aid. This project is just one of many funded by the NSF and is individually designed by each grant's Principal Investigators. Dr. Susan Terebey from the Physics/Astronomy Department and Dr. David Mayo from the Geology Department at CSULA, designed the SFOS project to allow the GK-12 fellow to enter the classroom not in the role of a science teacher but as a student scientist who can communicate to the students a deeper understanding of the science concepts that the students are actively studying and engaged in researching. This model has proved effective on several levels, for the GK-12 fellow, their partner-teacher and the students. 
One of the main motivations for creating these programs is the NSF's desire to support graduate level science students with fellowships to allow them to focus on science rather than the financial strains associated with obtaining a Masters of Science or Ph.D. degree in a scientific field. But more than a financial boost, the grant allows the fellow an intimate knowledge of K-12 science education, its strengths, weaknesses, and the level of science understanding of students in the public schools; this knowledge will not only benefit the fellow, but society as well. Should the fellow continue on, acquire a $\mathrm{Ph} \mathrm{D}$. and begin teaching at the college level, most likely he or she will teach entering freshmen straight out of high school, an audience they will now be intimately familiar with causing them to have a better rapport with their students. If the fellow decides to go into a position at an industry, they will also be familiar with the skill level(s) of the average worker, which helps them better communicate science in a market driven economy.

The partner teachers benefit from the student scientist by having a science resource person available ten hours per week who can communicate and explicate the more demanding aspects of the science curriculum to students in that way that integrates the fellows' "real life" experiences. For the science teachers, the benefit of the presence of the student scientist will continue years beyond the 10 hours per week. As the student scientists are in the classrooms answering questions, the teachers are also learning the answers, which they will in turn be able to share with their present and future students. The teacher also benefits financially. For participating in the SFOS program, partner teachers receive a substantial stipend, money for travel to professional development conferences and monies for classroom supplies.

Ultimately it is the K-12 students who benefit the most from this arrangement. As an example of science communication, one of the SFOS fellows, a physics student, took on the challenge of communicating to the high school students the nature of his research in nuclear magnetic resonance. This is not a topic that is normally addressed at the high school level, although related topics of magnetic fields and atomic theory are standards-based. He spent time working out an explanation that engaged the students by having them act out the measurement of the magnetic moment. That is, he had students get up out of their seats. He asked them to imagine that they were the nuclei of the molecules being measured. Initially, they were to stretch their arms pointed in random directions. At the signal, he would introduce a magnetic field, which would cause them to snap into an orientation all in one direction that would then gradually relax. The students were able to act out the story of the nuclear magnetic resonance measurement successfully. The SFOS fellow went on to show slides that described the technical details of the process. This graduate student scientist was not "teaching" the high school students. He was using several modalities-verbal, visual, kinesthetic - to communicate a science phenomenon.

The science teacher, on the other hand, recognized immediately that in order for high school students to understand the phenomenon of nuclear magnetic resonance, he would need to follow up with activities that connected to the students' base of prior knowledge. He disappeared into the science storeroom and came back with a variety of hands-on contraptions for students to experience other examples of the effect of magnetic fields. The teacher was aware of the pedagogical necessity to scaffold instruction, that is, to build from the students' existing understandings - prior knowledge - toward the level of expert science understanding communicated by the SFOS fellow. The actual process in this case is called "backmapping" (AAAS, 1998). From the advanced scientific discourse about nuclear magnetic resonance provided by the graduate student scientist, the science teacher mapped back toward the high school students' level of conceptual understanding in order to guide them toward a deeper understanding of the phenomenon presented by the SFOS fellow. This became achievable because the students' interest had been truly piqued by the dynamic style of science communication. As a team of science communicators, the student scientist and the science teacher helped the high school students attain a higher level of science literacy than would otherwise have occurred.

\section{CONCLUSION}

Science communication evokes the thrill of discovery, aims at telling the world about the significance of research results, and includes everyone in the world of science. Doing science is to investigate the unknown and to explain natural phenomena in terms of the evidence examined by methods of scientific inquiry. Science education applies pedagogical knowledge to the task of guiding learners toward meaningful understanding of the nature of science, science content, and the practical capabilities of doing science. Science literacy is the ability to follow the 
scientific discourse and to connect the world of science to the context of everyday life - the ability to make science personally relevant. By keeping these overlapping yet distinct vantage points clearly in mind science communication mediates a reconciliation between the non-science and science worlds.

This reconciliation needs to happen daily in the midst of school science. The AAAS Project 2061 lists "Ten Questions to Ask Your Neighborhood School About Local Science Education" on their website (AAAS, 1998). Questions such as "Is science literacy for all high-school graduates a major goal of the K-12 program?" or "What proportion of females and minorities are enrolled in advanced classes?" or "Are teachers given encouragement, time and to resources to update their own skills and knowledge?" and "Is learning active?" Having a student scientist in the classroom addresses and fulfills many of these questions head-on.

The SFOS project is designed to work with schools that are minority serving institutions. The fellowships have been awarded primarily to women science students and minority students. From an institutional standpoint the program involves student scientists who are more like the community of students they are serving. This helps instantly to break down barriers and encourages the classroom student to identify with the fellow, and to change their perceptions of who can be a scientist. Any public school that participates in a GK-12 program by its design encourages and gives the resource of a graduate student scientist to their teachers. This in turn allows for active learning to take place, opens lines of communication and creates a science learning environment that encourages rich discourse among a community of science seekers, learners and explorers!

The success of the SFOS project as part of the larger NSF-funded GK-12 program makes it clear that science communication advances the national effort to achieve science literacy. Yet, even so, it is difficult to carry successful projects beyond the initial seed money phase of funding. Sustaining these successes requires that communities encourage policy-makers and stakeholders to notice the importance and value of science communication, and find ways to continue bringing those who do, those who teach, and those who learn together into one world.

\section{ACKNOWLEDGEMENTS}

This manuscript is based on work supported by the National Science Foundation under Grant No. 0231993. Part of this work was carried out at the Jet Propulsion Laboratory, California Institute of Technology, under a contract with the National Aeronautics and Space Administration.

\section{REFERENCES}

1. American Association for the Advancement of Science, (1998). Blueprint for reform: Project 2061. New York: Oxford University Press.

2. Barman, C., (1997). "Students' Views of Scientists and Science: Results from a National Study". Science and Children V. 35, N. 1.

3. Brown, S., K. Bolton, N. Chadwell, and C. Melear, (2002). "Preservice Secondary Science Teacher Apprenticeship Experience with Scientists". In Proceeding of the Annual International Conference of the Association for the Education of Teachers in Science. (Charlotte, NC January 10-13, 2002)

4. $\quad$ Einstein, A. and L. Infeld, (1938). The Evolution of Physics. New York: Simon and Schuster.

5. Helmer, D.A., (1997). "Research experiences in teaching preparation: Effectiveness of the green bank preservice teacher enhancement program". (Doctoral dissertation, West Virginia University, 1997) Dissertation Abstracts International, 58, 07A.

6. Marek, E.A. and A.M.L. Cavallo, (1997). The learning cycle: Elementary school science and beyond. Portsmouth, New Hampshire: Heinemann.

7. McComas, W. F., (Ed.), (1998). The nature of science in science education: Rationales and strategies. Dordrecht, Netherlands: Kluwer Academic Publishers.

8. McLoughlin, C., (2003). "NCLB Primer for Parents and Educators: The Federal "No Child Left Behind" Act of 2001". National Association of School Psychologist. September.

9. National Research Council, (1996). National science education standards. Washington, DC: National Academy Press. 
10. National Science Foundation, (2001, June). "NSF graduate teaching fellows in k-12 education (GK-12)". (National Science Foundation). Available at www.nsf.gov/home/crssprgm/gk12/.

11. No Child Left Behind, 2001. (On-line) http://www.ecs.org/html/issue.asp?issueid=195\&subIssueID=101.

12. Odom, A. Lewis, J. Settlage, and J. Pederson, (2002). "Technology Knowledge and Use: A Survey of Science Educators". Journal of Technology Education V 11, N 4.

13. Patrina, S., (1998). "The politics of research in technology education: A critical content and discourse analysis of the Journal of Technology Education 10". Available at http://Scholar.lib.vt.edu/ejournals/ JTE/V10n1/petrina.html.

14. Raloff, J., (1998). "The Science of Museums". Science News V 154, N 12.

15. Shulman, L., (1987). "Knowledge and teaching: Foundations of the new reform". Harvard Educational Review, V 57, N 1.

16. Snow, C.P., (1964). The Two Culture and a Second Look. Syndics, New York: Cambridge University Press.

17. Stocklmayer, S.M., M.M. Gore, and C. Bryant, (Eds.), (2001). Science communication in theory and practice. Dordrecht, Netherlands: Kluwer Academic Publishers.

18. Thompson, S., V. Metzgar, A. Collins, M. Joeston, and V. Shepard, (2003). "Examining the Influence of a Graduate Teaching Fellows Program on Teachers in Grades 7-12". Journal of Geoscience Education V 51, N 1. Available at http://www.ed.psu.edu/CI/Journals/2002aets/t2_thompson_metzgar_c.rtf .

19. Ukpolo, F. and J. Strauss, (2005). "Pre-Service Teachers and No Child Left Behind". Journal of Urban Education: Focus on Enrichment V 2, N 2. (in press).

20. Valiela, I., (2001). Doing science: Design, analysis, and communication of scientific research. New York: The Oxford University Press.

21. Zukav, G., (1979). The Dancing Wu Li Master: An Overview of the New Physics. New York: William Morrow and Company.

\section{NOTES}




\section{NOTES}

